in the region of the liver a year or so before, with the immediate result that he was laid up for many weeks, but, even when asked if he could in any way account for the present disease, said he could not possibly do so, and it was only when he was directly asked at a second or third examination if he had ever had an injury of any sort that he referred to the accident. A similar difficulty was found in eliciting from a young and sturdy farming man, with basal empyema, that he had been crushed by a horse against a wall several months previously, although he had never been free from pain since that event. Mr. M'Gill's opinion as to the feasibility of an operation having been sought, he proposed to make an exploratory incision, and then to proceed according to the conditions disclosed. This was done on June 5 th, in the manner and with the result described below.

The patient being placed under the influence of ether, Mr. M'Gill made an incision, about four inches in length, half an inch below and parallel to the right costal margin, commencing two inches external to the linea alba. The abdominal muscles being divided, an opening about an inch long was made in the peritoneum, and the abdominal cavity opened. It was then seen that the upper surface of the liver was adherent to the diaphragm as far as the margin of the ribs, and distinct fluctuation could be felt by passing one finger on the under surface of the liver and another on the lowest part of the thoracic wall. The peritoneal wound was next closed with catgut sutures, and a trocar passed through the adhesion into the abscess cavity. The abscess cavity was opened by gradually dilating the opening made by the trocar, and ten ounces of pus were evacuated. The abscess was syringed with a weak ( 1 in 5000) solution of perchloride of mercury, the wound closed by catgut sutures, and dressed antiseptically. The spray was not used during the operation, but was used during the subsequent dressings.

The progress of the case was all that could be desired. The highest temperature was $100^{\circ} 4^{\circ}$ on the evening of the second day; on the third day the temperature was normal, and continued so. The drainage tube was gradually shortened, and removed at the end of a month. The patient left the hospital well on July 19th.

Remarks by Mr. M'GrLL.-The operation was performed first by making a long incision and opening the abdominal cavity; in this way the exact position of the adhesions was ascertained, and the abscess evacuated without fear of passing beyond their limits. By closing the opening in the peritoneum before opening the abscess all fear of escape of pus into the abdominal cavity was obviated. This method of operating is less dangerous and likely to be more successful than the more usual plan of cutting direct into the abscess cavity. Any danger that may be caused by the opening of the peritoneal cavity is counterbalanced by the precision and ease with which the exact position of adhesicns is ascertained, and the correct position for the opening of the abscess demonstrated.

\section{PEMBROKESHIRE AND HAVERFORDWEST} INFIRMARY.

SUPRA-PUBIC LITHOTOMY.-FIBROID TUMOUR OF ANTRUM.

(Under the care of Dr. JAMres WILSON.)

CASE 1.-Supra-pubic lithotomy complicated by stricture of the urethra; operation; recovery.-Morris $\mathrm{A}-\ldots$, aged forty-six years, a labourer, states that about twenty-seven years ago he suffered from intense pain in the back, which came on suddenly, lasted four days, and then ceased. For three months he wus quite well, then his urine became thick, and he noticed blood in it. There was also pain in the region of the bladder and in the penis, which eventually rendered him incapable of any physical exertion. Stone in the bladder was suspected, and he was sounded on different occasions by several surgeons, but the stone was not detected.

The man applied for admission at this infirmary in October, 1887, and came under the conjoint care of $\mathrm{Dr}$ E. P. Phillips and Dr. Wilson, On careful sounding they discovered a stone, which it was difficult to gauge accurately, owing to stricture of the urethra. The apparent size of the stone and the condition of the urethra were considered as indicating the supra-pubic operation as the best method for its removal.
On Oct. 27 th Dr. Wilson performed the operation with the assistance of Dr. Bennett, Dr. Phillips giving the A.C.E. mixture, in the presence of Drs. Stamper and Griffiths, who also kindly assisted. The stone was removed in the ordinary manner, and was found to measure an inch and a half by an inch and a quarter, with a thickness of half an inch. There was little or no hæmorrhage. The wound was partially closed by silver sutures, and a drainage tube retained in the bladder twenty-four hours. There was no sickness, and the patient was allowed milk and chicken soup.

Oct. 28 th.- The patient slept well on the previous night. Temperature $1005^{\circ}$; pulse 106 . The man's position was changed from side to side every six hours.

29 th.-Temperature $99^{\circ}$; pulse 90 . One ounce of urine was passed naturally, and fluid nourishment was taken freely.

30th.-Temperature $98^{\circ}$. The patient passed two ounces of urine.

From Oct. 31st to Nov. 6th all the urine escaped by the wound, and the patient's sides were uncomfortable from urinary excoriations.

Nov. 7th.-Patient passed three ounces of urine, followed by shivering, the temperature rising to $101^{\circ}$.

17th.-The escape from the wound has ceased. Granulations healthy, and the wound rapidly contracting.

20th. - Wound healed. Patient perfectly well, with the exception of slight cedema of the left lower extremity due to obstruction of the venous circulation; this quickly subsided.

CASE 2. Fibroid tumour of the antrum; removal of the right superior maxilla; recovery.-Ann $\mathbf{M}$ two, married, was admitted in March, 1887. She stated that she had a small tumour removed from the right side of the upper jaw about ten years ago, after which she felt no inconvenience for about eight years. She was then troubled with swelling of the cheek and prominence of the palate, from which there was frequent hæmorrhage.

On admission her cheek was prominent; there was thinning and expansion of the superior maxilla, with slight protrusion of the right eye; the orbital plate was not affected. The hard palate was absorbed on the right side and the margins of the erosion were abrupt, clean cut, and free from induration. The protruding portion of the tumour had a non-malignant appearance, and there was no enlargement of the lymphatic glands.

March 23rd.-Dr. Bennett gave the A.C.E. mixture, and, with the assistance of Dr. Stamper, Dr. Wilson removed the upper jaw. The wound was secured by silver sutures, and the cavity filled with lint dusted with iodoform powder. On examining the tumour after removal, it was found to consist of dense fibrous tissue, with a few spindle célls.

24th.- The patient had slept naturally on the previous night. Temperature $99.8^{\circ}$; pulse 102 . No pain; slight sickness. She took small quantities of milk.

26 th.-Temperature $99 \cdot 4^{\circ}$; pulse 90 , feeble. The woman slept well. Took six ounces of brandy. Appetite good.

27th.-Wound healed; sutures removed.

The patient left the infirmary three weeks after the operation. There has been no recurrence. She now enjoys good health, and the disfigurement is slight.

\section{算tedical Societies.}

\section{ROYAL MEDICAL \& CHIRURGICAL SOCIETY.}

\section{Occlusion of Left Bronchus; Successful Treatment.-Salicylic} Acid and its Influence on the Excretion of Uric Acid.

AN ordinary meeting of this Society was held on Tuesday last, Mr. G. D. Pollock, F.R.C.S., President, in the chair.

Dr. W. B. CheadLe and Mr. Thomas Smith introduced a case of Occlusion of the Left Bronchus by a Metal Pencil Cap, and its removal by Tracheotomy. The patient was a girl of nine years of age. The loose metallic cap covering the end of a pencil, which the child had put into her mouth, became detached, and was drawn into the throat. Urgent choking and dyspnce followed. This was relieved atter the passage of a probang down the cesophagus, and the foreign body was believed to have entered the stomach. There was great pain at the time and violent cough. Four days later dulness on 